\title{
Cloning of Octopus cephalotocin receptor, a member of the oxytocin/vasopressin superfamily
}

\author{
Atsuhiro Kanda, Kyoko Takuwa-Kuroda, Eiko Iwakoshi-Ukena, \\ Yasuo Furukawa ${ }^{1}$, Osamu Matsushima ${ }^{1}$ and Hiroyuki Minakata \\ Suntory Institute for Bioorganic Research, 1-1-1 Wakayamadai, Shimamoto, Mishima, Osaka 618-8503, Japan \\ ${ }^{1}$ Department of Biological Science, Faculty of Science, Hiroshima University, 1-3-1 Kagamiyama, Higashi-Hiroshima 739-8526, Japan \\ (Requests for offprints should be addressed to H Minakata; Email: minakata@sunbor.or.jp)
}

\begin{abstract}
We reported that the common octopus, Octopus vulgaris, in common with vertebrates, possesses two members of the oxytocin/vasopressin superfamily: octopressin (OP) and cephalotocin (CT). This was the first observation of its kind in invertebrates. As OP and CT have different biological activities, the presence of specific receptors has been proposed. We cloned the cDNA of an orphan receptor from Octopus brain and found it to encode a polypeptide of 397 amino acids that displays sequences characteristic of G-protein coupled receptors. The orphan receptor showed high homology to receptors of the oxytocin/vasopressin superfamily and seemed to conserve the agonist-binding pocket common to the oxytocin and vasopressin receptors. Xenopus oocytes that express the orphan receptor responded to the application of CT by an
\end{abstract}

induction of membrane $\mathrm{Cl}^{-}$currents coupled to the inositol phosphate/ $\mathrm{Ca}^{2+}$ pathway. OP and the other members of the oxytocin/vasopressin superfamily did not activate this receptor. HPLC fractionation of the Octopus brain extract combined with an oocyte assay yielded a single substance that was identical to CT. On the basis of these results, we conclude that the cloned receptor is the CT receptor (CTR). Expression of CTR mRNA in Octopus was detected in the central and the peripheral nervous systems, the pancreas, the oviduct and the ovary. This receptor may mediate physiological functions of CT in Octopus such as neurotransmission, reproduction and metabolism.

Journal of Endocrinology (2003) 179, 281-291

\section{Introduction}

Oxytocin (OT) and vasopressin (VP) are nonapeptides that are present in all placental mammals. Although they are similar in structure, they serve different functions. OT has uterotonic and milk-ejection activities and regulates aspects of reproductive behaviour, whereas VP has antidiuretic activities and is involved in hydromineral regulation.

Members of the OT/VP superfamily are widely distributed in both invertebrates and vertebrates, and have key roles as signalling molecules in the regulation of reproduction and osmotic balance (reviewed by Gimpl \& Fahrenholz 2001). In invertebrates, they include VPlike diuretic hormone from the locust Locusta migratoria, annetocin from the earthworm Eisenia foetida, Lys- and Arg-conopressins from the gastropod molluscs Conus geographus, Conus striatus and Lymnaea stagnalis (reviewed by Hoyle 1998) and cephalotocin (CT) from the cephalopod mollusc, Octopus vulgaris (Reich 1992). Although all vertebrate species except for cyclostomes have peptides from both the OT and the VP families, invertebrate species examined to date have usually possessed only a single peptide belonging to the OT/VP superfamily. We showed previously that, in addition to CT, Octopus possesses another member of the OT/VP superfamily, octopressin (OP) (Takuwa-Kuroda et al. 2003). This was the first report of the co-occurrence of two members of the superfamily in a single invertebrate species. Because OP, but not $\mathrm{CT}$, induced contractile activity in smooth muscles of several Octopus tissues, we proposed that there are more than two distinct receptors in the octopus for members of the oxytocin/vasopressin superfamily (Takuwa-Kuroda et al. 2003).

Receptors of the OT/VP superfamily are generally G-protein coupled receptors (GPCRs), a superfamily of proteins characterized by seven transmembrane-spanning domains. GPCRs mediate the actions of numerous neurotransmitters and hormones (Probst et al. 1992). The V2 receptor mediates the antidiuretic effects of $\mathrm{VP}$ and couples positively to adenylate cyclase (Lolait et al. 1992, Gorbulev et al. 1993). The OT receptor (Kimura et al. 1992, Gorbulev et al. 1993) mediates various central and peripheral functions in reproduction in mammals. V1a (Thibonnier et al. 1994) and V1b (Sugimoto et al. 1994) 
Table 1 Sequences of primers

\section{Sequence}

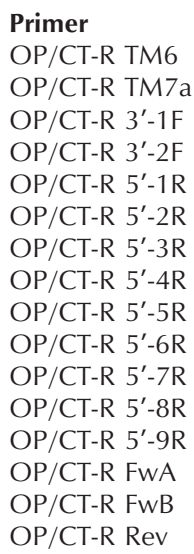

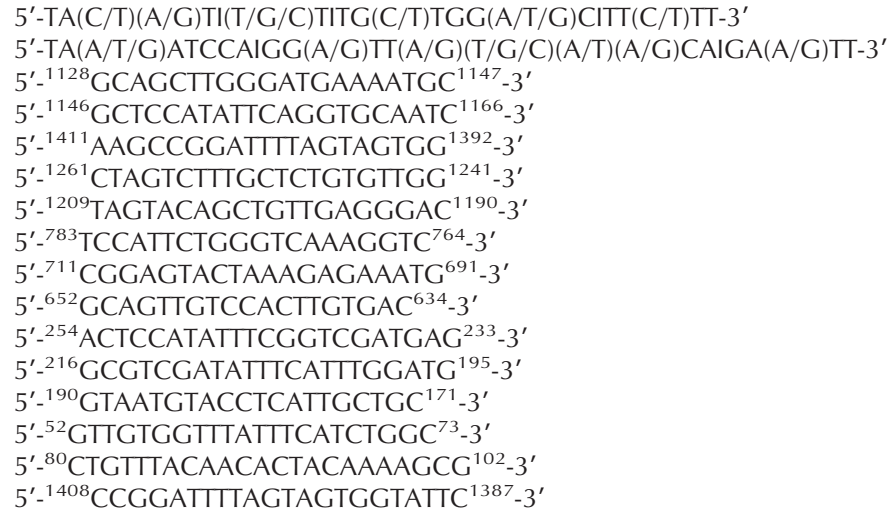

I, inosine.

receptors mediate the effects of $\mathrm{VP}$ on liver glycogenolysis and the release of adrenocorticotropin, respectively. Similar effects of OT on the liver are also mediated by the OT receptor. These receptors couple to the inositol phosphate $/ \mathrm{Ca}^{2+}$ signal transduction pathway.

In invertebrates, the cloning of two Lys-conopressin receptors, LSCPR1 and LSCPR2, from Lymnaea has been reported (van Kesteren et al. 1995, 1996). These receptors are expressed in different tissues and mediate both functions of OT-like reproduction and VP-like glycogenolysis of Lys-conopressin in Lymnaea.

We report here the cloning of an octopus homologue of the OT/VP receptor from the brain of Octopus. The receptor, named CT receptor (CTR), is a GPCR that is specific to CT. Because CTR mRNA was detected in the central and the peripheral nervous systems, the pancreas, the oviduct and the ovary, CTR may mediate physiological functions such as neurotransmission, reproduction and metabolism.

\section{Material and Methods}

Animals

Adult octopuses (Octopus vulgaris, ca. $2 \mathrm{~kg}$ ), were purchased from a local fish shop, and kept in artificial seawater at $18{ }^{\circ} \mathrm{C}$.

\section{Preparation of total RNA}

Total RNA was prepared using Sepasol-RNA I Super (Nacalai Tesque, Kyoto, Japan) according to the manufacturer's instructions.

\section{Oligonucleotide primers}

Oligonucleotide primers were purchased from Qiagen and Kiko-tech (Osaka, Japan). Degenerate primers, OP/
CT-R TM6 and OP/CT-R TM7a, were designed that were based on sequences in the sixth and seventh transmembrane domains, respectively, both of which are conserved among the receptors of the OT/VP superfamily in vertebrates and Lys-conopressin receptors. All primers used are listed in Table 1.

\section{Cloning of partial-length $c D N A$}

All PCR amplifications were carried out in a reaction mixture containing Ex Taq polymerase (Takara Shuzo, Kyoto, Japan) and $200 \mu \mathrm{M}$ dNTP in a thermal cycler (GeneAmp PCR System 9700; Applied Biosystems Japan, Tokyo, Japan). To confirm the fidelity of Taq polymerase, several sets of clones (at least four clones) were sequenced in every PCR experiment. First-strand cDNA was synthesized with the oligo(dT)-anchor primer supplied in the $5^{\prime} / 3^{\prime}$-RACE kit (Roche Diagnostics, Basel, Switzerland). PCR was performed using OP/ CT-R TM6 and OP/CT-R TM7a under the following conditions: $5 \mathrm{~min}$ at $94{ }^{\circ} \mathrm{C} ; 50$ cycles of $30 \mathrm{~s}$ at $94{ }^{\circ} \mathrm{C}$, $30 \mathrm{~s}$ at $50{ }^{\circ} \mathrm{C}, 1 \mathrm{~min}$ at $72{ }^{\circ} \mathrm{C}(7 \mathrm{~min}$ for the last cycle $)$. PCR products separated by $1.5 \%$ agarose gel electrophoresis were purified using Qiaquick Gel Extraction kit (Qiagen), and subcloned into the pDrive Cloning vector using a Qiagen PCR cloning kit and transformed into Escherichia coli DH5a (TOYOBO, Tokyo, Japan). Sunbcloned inserts were sequenced on an ABI Prism 310 Genetic Analyser (Applied Biosystems Japan) using a Big-Dye sequencing kit version 3 (Applied Biosystems Japan) and analysed on Genetyx-Mac software (Software Development, Tokyo, Japan). Universal M13 primers or gene-specific primers were used to sequence both strands. 


\section{3'-Rapid amplification of $c \mathrm{DNA}$ ends}

First-strand cDNA was synthesized with the oligo(dT)anchor primer supplied in the $5^{\prime} / 3^{\prime}$-RACE kit (Roche Diagnostics). The first PCR was performed using the PCR anchor primer and OP/CT-R $3^{\prime}-1 \mathrm{~F}$ under the following conditions: $5 \mathrm{~min}$ at $94{ }^{\circ} \mathrm{C} ; 30$ cycles of $30 \mathrm{~s}$ at $94{ }^{\circ} \mathrm{C}, 30 \mathrm{~s}$ at $50{ }^{\circ} \mathrm{C}, 2 \mathrm{~min}$ at $72{ }^{\circ} \mathrm{C}(7 \mathrm{~min}$ for the last cycle). The second PCR was performed using the PCR anchor primer and OP/CT-R 3'-2F under the following conditions: $94{ }^{\circ} \mathrm{C}$ for $5 \mathrm{~min} ; 30$ cycles of $30 \mathrm{~s}$ at $94{ }^{\circ} \mathrm{C}, 30 \mathrm{~s}$ at $51{ }^{\circ} \mathrm{C}, 2 \mathrm{~min}$ at $72{ }^{\circ} \mathrm{C}(7 \mathrm{~min}$ for the last cycle). The second PCR products were subcloned and sequenced as described above.

\section{$5^{\prime}$-Rapid amplification of $c D N A$ ends}

Three sets of template cDNAs were synthesized using as primers OP/CT-R 5'-1R, OP/CT-R 5'-4R and OP/ CT-R 5'-7R, and tailed by dA using dATP and terminal transferase (Roche Diagnostics). The first template was amplified using the oligo(dT)-anchor primer and OP/ CT-R $5^{\prime}-2 \mathrm{R}$. The remaining two templates were also amplified between the anchor primer and OP/CT-R $5^{\prime}-5 \mathrm{R}$, and between the anchor and OP/CT-R 5'-8R, respectively. Each of the first PCR products was reamplified using the anchor primer and OP/CT-R $5^{\prime}-3 \mathrm{R}$, OP/CT-R 5'-6R or OP/CT-R 5'-9R. Both first and second PCR were performed for 5 min at $94^{\circ} \mathrm{C} ; 30$ cycles for $30 \mathrm{~s}$ at $94{ }^{\circ} \mathrm{C}, 30 \mathrm{~s}$ at $52{ }^{\circ} \mathrm{C}$, and $2 \mathrm{~min}$ at $72{ }^{\circ} \mathrm{C}(7 \mathrm{~min}$ for the last cycle). The second PCR products were subcloned and sequenced as described in the previous section. Full-length cDNA was obtained using primers, OP/CT-R FwA and OP/CT-R Rev, and the following PCR conditions: $5 \mathrm{~min}$ at $94{ }^{\circ} \mathrm{C} ; 50$ cycles for $30 \mathrm{~s}$ at $94{ }^{\circ} \mathrm{C}, 30$ s at $50{ }^{\circ} \mathrm{C}$, and $2 \mathrm{~min}$ at $72{ }^{\circ} \mathrm{C}(7 \mathrm{~min}$ for the last cycle). Thus a 1706 bp-long cDNA encoding an orphan receptor was obtained.

\section{RT-PCR Southern blot analysis}

Each of total RNAs $(1 \mu \mathrm{g})$ extracted from various tissues was reverse-transcribed by Superscript II (Invitrogene, Groningen, The Netherlands) using oligo $\mathrm{dT}_{12-18}$ primer. The first PCR was performed using OP/CT-R FwA and OP/CT-R 5'-1R under the following conditions: $5 \mathrm{~min}$ at $94{ }^{\circ} \mathrm{C} ; 50$ cycles of $30 \mathrm{~s}$ at $94{ }^{\circ} \mathrm{C}, 30 \mathrm{~s}$ at $50{ }^{\circ} \mathrm{C}, 1 \mathrm{~min}$ at $72^{\circ} \mathrm{C}$ (7 min for the last cycle). The second PCR was performed using OP/CT-R FwB and OP/CT-R Rev under the following conditions: $94^{\circ} \mathrm{C}$ for 5 min; 20 cycles of $30 \mathrm{~s}$ at $94{ }^{\circ} \mathrm{C}, 30 \mathrm{~s}$ at $50{ }^{\circ} \mathrm{C}, 1 \mathrm{~min}$ at $72{ }^{\circ} \mathrm{C}(7 \mathrm{~min}$ for the last cycle). The second PCR products were separated by $1.5 \%$ agarose gel electrophoresis, and then transferred onto Hybond- $\mathrm{N}^{+}$membrane (Amersham) and crosslinked by UV irradiation. Hybridization and detection were processed according to the manufacturer's procedure (Roche Diagnostics). The cDNA of the orphan receptor was labelled with the DIG DNA labelling kit (Roche Diagnostics) and used as a probe for Southern blotting according to the manufacturer's instructions. The partial cDNA of Octopus actin (AB053937) amplified by the primer set (position 25-44 and position 595-614) was hybridized and detected by the DIG-labelled oligonucleotide (position 347-366) as an internal control. As a negative control, the extracted total RNAs, which were not reverse transcribed, were used as templates for PCR, and it was confirmed that there was no amplification of traces of the genomic DNA.

Expression of the cloned orphan receptor in Xenopus oocytes

The open reading frame region of the orphan receptor cDNA was amplified and inserted into a pSP64 poly(A) vector (Promega). The plasmid was linearized with EcoRI, and cRNA was prepared using SP6 RNA polymerase (Ambion, Austin, TX, USA). Fifty nanolitres of the cRNA solution $(0.05 \mu \mathrm{g} / \mu \mathrm{l})$ was injected into Xenopus oocytes. The oocytes were incubated for $2-4$ days at $17^{\circ} \mathrm{C}$ in ND96 buffer [96 mM NaCl, $2 \mathrm{mM} \mathrm{KCl}, 1 \cdot 8 \mathrm{mM}$ $\mathrm{CaCl}_{2}, 1 \mathrm{mM} \mathrm{MgCl}_{2}$ and $5 \mathrm{mM}$ HEPES (pH 7.6)]. The oocytes were voltage-clamped at $-80 \mathrm{mV}$. Peptides diluted with ND96 buffer were applied to the oocytes every $15 \mathrm{~min}$ to prevent desensitization of the receptor at concentrations between $10^{-10}$ and $10^{-6} \mathrm{M}$. Four oocytes were tested at each concentration to obtain a doseresponse relationship. OP and CT were synthesized with a solid-phase peptide synthesizer using standard Fmoc chemistry (Model 433A, Applied Biosystems Japan). Peptides of the OT/VP superfamily and antagonists for OT, V1 and V2 receptors were purchased from Bachem (Bubendorf, Switzerland). A mixture of an antagonist and a peptide was dissolved in the buffer at $10^{-5} \mathrm{M}$ and $10^{-7} \mathrm{M}$. The dose-response data were analysed using ORIGIN 6.1 software (Microcal Software Inc., Northampton, MA, USA) to estimate the $\mathrm{EC}_{50}$ value.

Isolation and structure determination of an endogenous ligand of the orphan receptor from Octopus brain

The methods for dissection, extraction and purification were the same as those previously described (Iwakoshi et al. 2000). Briefly, the suboesophageal brain (10 g) was boiled in water and extracted with 3\% acetic acid. The extract was applied to a solid-phase extraction column (Sep-pak Vac C18, Waters, Milford, MA, USA). The retained material was eluted with $60 \%$ acetonitrile in $0 \cdot 1 \%$ trifluoroacetic acid (TFA), and condensed in vacuo. The residue was dissolved in $0 \cdot 1 \%$ TFA and fractionated by a linear gradient elution of $0-36 \%$ acetonitrile in $0 \cdot 1 \%$ TFA at a flow rate of $1.5 \mathrm{ml} / \mathrm{min}$ on a reversed-phase HPLC with a C18 column (Capcell Pak C18 UG80 $10 \mathrm{~mm}$ $\times 250 \mathrm{~mm}$, Shiseido, Tokyo, Japan). Fractions were 
collected every 2 min. A 1/100 aliquot of each fraction was condensed to dryness in vacuo, dissolved in ND96 buffer and then assayed in the Xenopus oocyte that expressed the orphan receptor. The active fractions were further purified by using the following columns: a cationexchange column (TSKgel SP-5PW, $7.5 \mathrm{~mm} \times 75 \mathrm{~mm}$, Tosoh, Tokyo, Japan; 0-0.6 M NaCl/60-min linear gradient in $20 \mathrm{mM}$ phosphate buffer, $\mathrm{pH} 7 \cdot 0$, flow rate of $1.5 \mathrm{ml} / \mathrm{min}$, fraction $/ 2 \mathrm{~min}$ ), a C18 column (Capcall Pak C18, MG80, $4.6 \mathrm{~mm} \times 250 \mathrm{~mm}$, Shiseido; $18-30 \%$ acetonitrile in $0 \cdot 1 \%$ TFA $/ 40$-min linear gradient, flow rate of $1.0 \mathrm{ml} / \mathrm{min}$, fraction $/ 1 \mathrm{~min})$. In the assay of cationexchange HPLC fractions, 1/100 aliquot of each fraction was diluted in ND96 buffer, and applied to the assay chamber.

The active peak from the third C18 HPLC was subjected to amino acid sequencing (PSQ-1; Shimazu, Kyoto, Japan). The molecular weight was determined by nanoflow electrospray ionization time-of-flight mass spectrometry (nano ESI-TOF-MS) (Q-TOF; Micromass UK, Wythenshawe, UK). The molecular mass peak was further examined in nano ESI-TOF-MS/MS analysis. The capillary voltage was optimized at $1200 \mathrm{~V}$ and the cone voltage was set at $50 \mathrm{~V}$. Argon was used as the collision gas and the energy was set at $25 \mathrm{~V}$.

\section{Results}

Cloning and structure of an Octopus receptor of the OT/VP superfamily

Within the amino acid sequences of the known receptors of the OT/VP superfamily, in both vertebrates and invertebrates, those of the sixth and seventh transmembrane domains are highly conserved. To identify receptors for OP and CT in Octopus, two degenerate primers were designed that were based on the conserved region, and PCR was performed between these primers. PCR products with the expected size of $134 \mathrm{bp}$ were cloned and sequenced. The encoded protein fragment showed the greatest homology with structures for receptors of the OT/VP superfamily found in a database, DDBJ. The full-length cDNA sequence (1706 bp) encoding a putative $\mathrm{OP} / \mathrm{CT}$ receptor was determined using the $5^{\prime}-$ and 3'-RACE methods (Fig. 1A). It has an open reading frame of 397 amino acids and contains $176 \mathrm{bp}$ of $5^{\prime}$-untranslated and $336 \mathrm{bp}$ of $3^{\prime}$-untranslated sequences with two polyadenylation signals (AATAAA) $113 \mathrm{bp}$ and $244 \mathrm{bp}$ upstream from the poly(A) tail. The nucleotide sequence was deposited into the DDBJ/EMBL/GeneBank databases under the accession number AB090945.

Several sets of clones in every PCR were analysed and gave exactly the same nucleotide sequence in each experiment, thus confirming the fidelity of Taq polymerase.

Hydrophobicity analysis of the predicted amino acid sequence revealed seven hydrophobic domains character- istic of GPCR (Fig. 1B). The orphan receptor has two Cys residues at positions 118 and 194 in the first and second extracellular loops. These residues are highly conserved within GPCR and are probably connected by a disulphide bridge. As shown in Fig. 1A, the sequence displays several other characteristics of GPCR such as $N$-linked glycosylation sites (Asn-X-Ser/Thr; Asn ${ }^{18,27,33}$ ) in the N-terminal extracellular domain, consensus sequences for phosphorylation by protein kinase A (Arg/Lys-X-(X)-Ser/Thr; $\mathrm{Ser}^{240,251,258,271,287,362,386}$, $\left.\mathrm{Thr}^{78,241,259,361}\right)$, by protein kinase C (Ser/Thr-X-Arg/Lys; Ser ${ }^{153,244,258,377,386 \text {, }}$ $\mathrm{Thr}^{158,254,361,394}$ ), and by casein kinase II (Ser/Thr-X-XAsp/Glu; Ser $\left.{ }^{271,378}\right)$. The orphan receptor has an Asp ${ }^{91}$ in transmembrane domain II and a tripeptide (Asp-Arg-Tyr) at the interface of transmembrane III and the first intracellular loop. These residues are believed to be important for receptor activation (Bockaert \& Pin 1999). These results suggest that the cloned orphan receptor is a member of the GPCR family.

An amino acid sequence alignment of the cloned receptor and receptors of the OT/VP superfamily is presented in Fig. 2. The sequence homologies of the cloned receptor were estimated as follows: $42.5 \%$ human V1a, 39.9\% human V1b, 35.5\% human V2, $42 \cdot 2 \%$ chicken vasotocin, $41 \cdot 1 \%$ white sucker vasotocin, 39\% human OT, $42 \cdot 2 \%$ toad mesotocin, $39 \cdot 4 \%$ white sucker isotocin, $43 \cdot 2 \%$ Lymnaea LSCPR1, and 37.9\% Lymnaea LSCPR 2. Several amino acid sequences (Phe-Gln-ValLeu-Pro-Gln-Leu at the C-terminal end of transmembrane domain II, Gly-Pro-Asp in the first and Asp-CysTrp and Pro-Trp-Gly in the second extracellular loop) that are conserved among receptors of the OT/VP superfamily in vertebrates are considered to be important for ligand binding (Sharif \& Hanley 1992) (Fig. 2). In the cloned receptor, these sequences are somewhat homologous, namely, Phe-Asn-Asn-Leu-Pro-Gln-Met, Gly-Thr-Asp, Thr-Cys-Gln, and Glu-Trp-Thr. Such amino acid substitutions also occurred in LSCPR1 and LSCPR2. On the basis of these results, we suggest that the cloned receptor is a homologue of receptors of the OT/VP superfamily.

\section{Functional expression of the cloned receptor in Xenopus oocyte}

If the cloned receptor can couple to Gq protein of Xenopus oocyte, active ligands will exhibit $\mathrm{Cl}^{-}$current mediated by the inositol phosphate $/ \mathrm{Ca}^{2+}$-signalling pathway. The voltage-clamped oocytes expressing the cloned receptor displayed inward membrane currents after the application of $\mathrm{CT}$ at $10^{-7} \mathrm{M}$ (Fig. 3A). In contrast, OP did not trigger the current even at $10^{-6} \mathrm{M}$ (Fig. 3B). We also tested both vertebrate and invertebrate peptides belonging to the OT/VP superfamily (VP, vasotocin, annetocin, Lys-conopressin, or Arg-conopressin), but they had no effects even at $10^{-5} \mathrm{M}$ (data not shown). Among the tested peptides, only OT caused a weak effect at $10^{-6} \mathrm{M}$ 
(A)

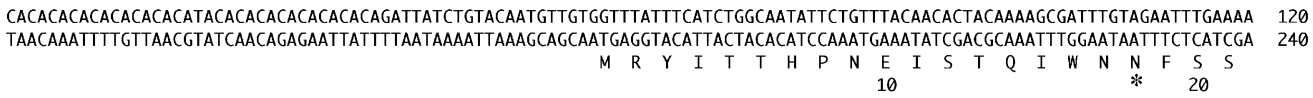

CCGAAATATGGAGTAACTTTTCCGCAGCAAAAAATGAAACTCAGCCCATAAGACGTAATCAAGACCTGGCTAATGCTGAAGTTATTACGTTGGCTGTTGTTATAATAATTACAGTTATAG 360

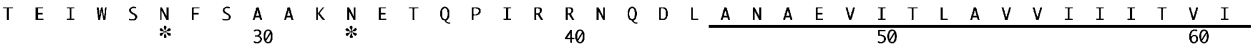
GTAATAGTATTGTTTTAATAACATTGTTCCAGCGTAGAAAGAAACTGACACGAATGCACCTGTTTATTTTACACCTGTCTGTAACTGACCTCTTCGTCGCCTTCTTTAATAATTTGCCGC 480

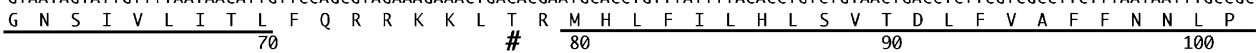

AGATGATTTGGGACATTACATTTTTATTTCTTGGAACTGATTTACTGTGTCGTCTCGTTACTTACTTACAAAGCGTAGCTATGTATGCATCGAGCTATGTCCTTGTGGCAACAGCTATTG 600

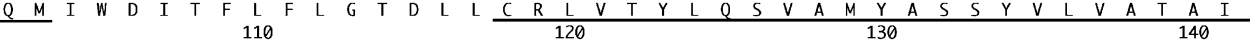

ACCGTTATTTTGCTATATGTCACCCTTTATCAAGTCACAAGTGGACAACTGCCAGAGTACACGTCATGGTTTTCATTGCCTGGATGTTATCATTTCTCTTCAGTACTCCGCAGCTCTTCA 720

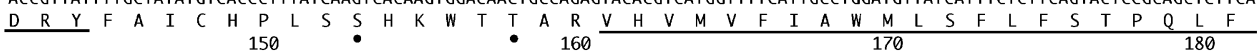

TATGGAGCATGCAGTTCTCAAATATTGGATTGACTTGTCAGGCGACCTTTGACCCAGAATGGACTCTGAAATTTTATATCACTTGGTTAACAGTCGCGATTTGGATTTTACCAACAATAG 840

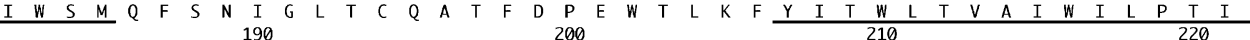

CACTGACTCTGTTTTATGGAATGATGTGCTTTGCTGTATGGAAAAGAGGACGTTCTACTTTGGGCAGTTCCCGAACACGAAATAGATCTTITCTCACGAATCGTGTGTCTACACGTATTG 960

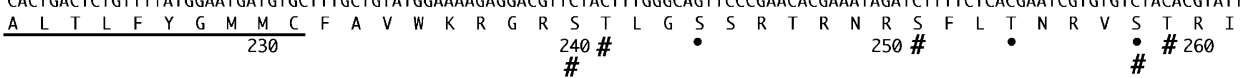
GTCAAAGCCATTTAGCTCGAGGGTTTTCCGAAGAGGATATGGAAGGACAAAGCGTCAATTACAACAGAGGAATTTCTCGAGCCAAAGTCCGGTCTGTGGCTCTAACTTTAAGTGTGGTTG 1080 $\left.\begin{array}{llllllllllllllllllllllllllllllllllllllll}G & Q & S & H & L & A & R & G & F & S\end{array}\right]$ CCTGTTACTTTATATGTTGGTCACCGTTTTTTGTGTGTCAGATGTGGGCAGCTTGGGATGAAAATGCTCCATATTCAGGTGCAATCTATACGATATTATTGCTACTCTCGTCCCTCAACA 1200

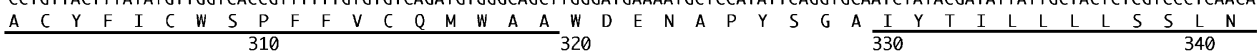
GCTGTACTAATCCCTGGATTTACATGATCTTTAGTGTATTCCAACACAGAGCAAAGACTAGTCGCTTTGTTAATGACGAAGAAACGACCTCAGTGACTGTGCTGTCATCTAGGAATGATA 1320

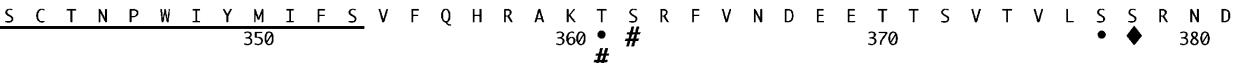
TCAGATTGATGTCAATGAAGAAGAAATTGGAACAAACAGCCAGAAACTGAAAAAATTCAGAAAATTGAATACCACTACTAAAATCCGGCTTCCATTATGTTGGTAATTTGAGTGACATGT 1440 \begin{tabular}{lllllllllllllll}
$\mathrm{I}$ & $\mathrm{R}$ & $\mathrm{L}$ & $\mathrm{M}$ & $\mathrm{S}$ & $\mathrm{M}$ & $\mathrm{K}$ & $\mathrm{K}$ & $\mathrm{K}$ & $\mathrm{L}$ & $\mathrm{E}$ & $\mathrm{Q}$ & $\mathrm{T}$ & $\mathrm{A}$ & $\mathrm{R}$ \\
\hline
\end{tabular}

TAATAAACTGGAAGAACAACAGAATATTTAGAACAATTTTAAGTGCAAACGTAAATTCAATTTCCTGTGTACGTATATGATATGGATGTATGCATATAAGTATACTTGCATGTGTACTGA 1560 TATATATATGTAAATAAATATATAGAAATACACGCATACACTCAAAAGCACGCATACGCAACACCGCCAGATATACCTGTAAACCTACTTATACGTATACATGCTTACAGTCCCACACTT 1680 CACGCATACTAAAAAAAAAAAAAAAA 1706

(B)

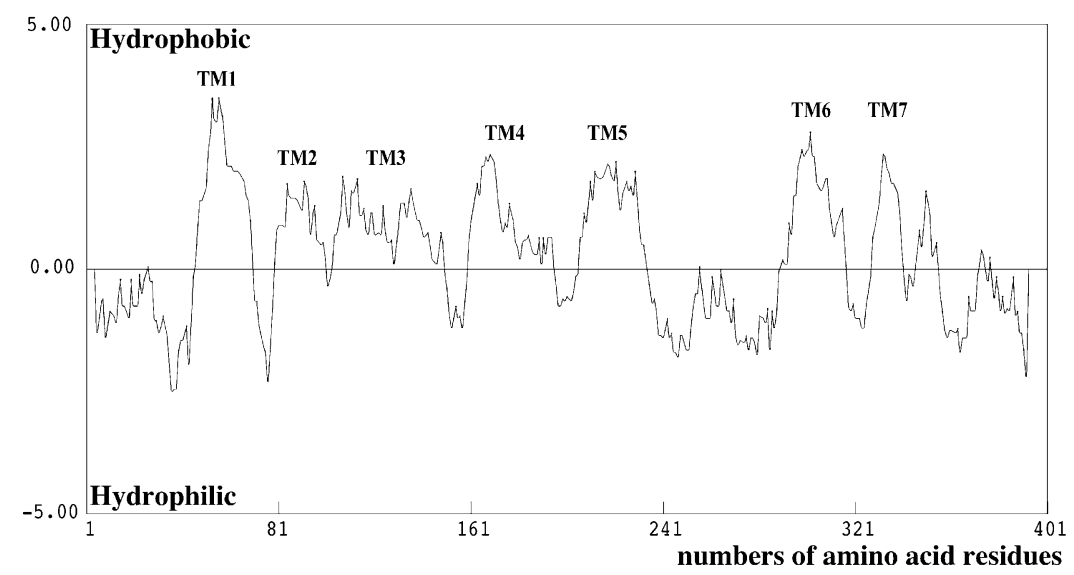

Figure 1 Primary structure of the precursor of the cloned orphan receptor. (A) Nucleotide sequence and deduced amino acid sequence of the precursor of the orphan receptor cloned from the Octopus brain. The transmembrane regions are underlined. *, N-Linked glycosylation sites. Potential phosphorylation sites:

- protein kinase C; \#, protein kinase A; $\bullet$, casein kinase II. The polyadenylation signals (AATAAA) are in boxes. (B) Hydrophobicity plot of the orphan receptor according to Kyte \& Doolittle (1982). 
CTR

LSCPR1

LSCPR2

OT-human

V1a-human

V2-human

TM1

1 -MRYITTHPNEISTOIWNNFSSTEIWSNFSAAKNETOPIRRNQ-DLANAEVITLAVVIIITVIGNSIVLITLF-ORRKKLT-RMHLFILHLSVTDL -MDLELNLTNGFMLMPPTKRAVIOIASNEKVGYDVSKSOPVNATTDL NTTRMNATNSTEVSYFHGVDEDLLKIEIAVOATILYMTLFGNGIVLLVLR-LRROK-LTRMOWFIAHLAFADI 作 _ MEGALA-ANWSAEAANASAAPPGAEGNRTAGPPRRNEALARVEVAVLCLILLLALSGNACVLLALRT-TRQKHS-RLFFFMKHLSIADL -MRLSAGPDAGPSGNSSPWWLATGAGNTSREAEALGEGNGPPRDVRNEELAKLEIAVLAVTFAVAVLGNSSVLLALHRTPRKTS- -RMHLFIRHLSLADL 作 I MLMASTTSAVPGHPSLPSLPSNSSQERPLDTRDPLLARAELALLSIVFVAVALSNGLVLAALARRGRRGHWAPIHVFIGHLCLADI $* * * * * * * * * *$

TM3

TM4

$93 \overline{\text { FVAF FNNLPQM }}$ WDITFI FI GTDLLCRLVTYLOSVAMYASSYVLVATAIDRYFAICHPLSSHKWTTARVHVM-VFIAWMLSFLFSTPQLFIWSMOFSNIGL- - $\overline{\text { TCQA }} \overline{\text { GFPPEWTLKFYI }}$ LSCPR1 118 FVGFFNILPQL ISDVTIVFHGDDFTCRFIKYFOVIAMYASSYVLVMAAIDRYLSICHPLTSOTLSPKRVHLM - IALAWLISFLCALPQVFIFSLQAVGPDQ - - YDCLATFEPDWGMQAYI

ISCPR2

OT-human

V1a-human

V1b-human

V2-human

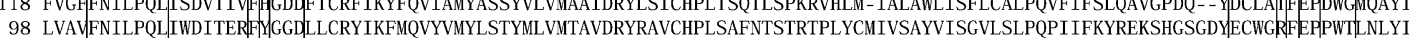

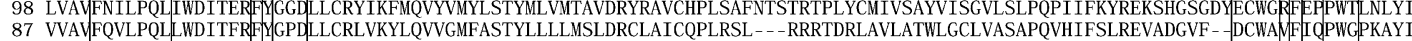
99 AVAF FQVLPQMCWDITYR FR GPDWLCRVVKHLQVFGMFASAYMLVVMTADRYIAVCHPLKTLQQPARRSRLM - IAAAWVLSFVLSTPQYFVFSMIEVNNVTKARDCWATF IOPWGSRAYV 82 AVAI FOVLPOI LWDITYRFOGPDLLCRAVKYLOVLSMFASTYMLLAMTLDRYLAVCHPLRSLOQPGOSTYLL - IAAPWLLAAIFSLPOVFIFSLREVIOGSGVI DCWADFGFPWGPRAYI 80 AVAL FOVLPOLAWKATDR ERGPDALCRAVKYLQMVGMYASSYMILAMTLDRHRAICRPMLAYRHGSGAHWNRPVLVAWAFSLLLSLPQLFIFAQRNVEGGSGVTDCWACEAEPWGRRTYV

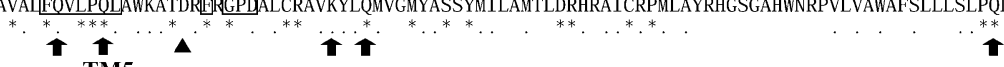
M5

CTR
LSCPR1

OT-human

V1a-human

V1b-human

V2-human

209 TWLTVAIWIL-PTIALTLFYGMMCFAVWKRGRSTLGSSRTRNRSFLTNRVSTRIGQSHLARGFSEED -

MECQSVNYNRGISRAKVRSVA 235 TWVFVANYVI - PFLLLAFCYGRICHVVWMSVAAKESAAYSSMRNGCTESSRPIKMRISFHRRRDNTN - ATLTSLDRHDASAVTSSDSKKPRGHORGVSKSKMKTIKLTLTVVLCYLFCWA 218 TSFTFAVYIV-PLAILIFAYVSICCTIWRKYKSAENERKHMLNGSDSSLGNRNIYSNHVTHSALFRHRGVIERRRNLVQRCRPAPMAAPRAHSLRGFSRAKLKTVKLTFVVIVAYVVCWS 202 TWITLAVYIV-PVIVLAACYGLISFKIWQ-NLRLKTAAAAAAEAPEGAAAGDGGRVALA 218 TWMTGGI-FVAPVVILGTCYGFICYNIWCNV-RGKTASRQSKGAEQAGVAFQKGFLLAP_

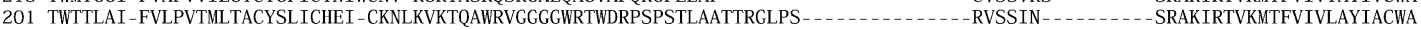
207 TWIALMV-FVAPTLGIAACQVLI-FREIHASLVPGPSERPGGRRRGRRTGSPGEGAHV * . . . * * * * * * *

TM7

CTR

LSCPR1

LSCPR2

OT-human

V1a-human

V1b-human

V2-human

310 PFFVCQMWAAWDENAPY -- SGAIYTILLLLSSLNSCTNPWIYMIFSVFQHRAKTSRFVNDEETTSVTVLSSRNDIRLUSMKKKLEQTARN 353 PFFVVQMWSAFDDDSGIE--EHPVTVICMLLASLNSCTNPWIYLAFSGRTCQRNHANRNTSRSWGPSTHVTSGGDSHEFKTRSSFIDLSHARERIHHHRDGMNARSSSPRFSEMNKLNHS 337 PFFLSQLWWLYDEQQ- -E- -HNHAVVIMVLLASLNSCCNPWIYLAFSGNLIRHICPMRPNSRNCCCCDLRRCRRRQFYRRRSSSNNNHDDTHSPLSPSDMLDDMELRELIADGINRKRQP

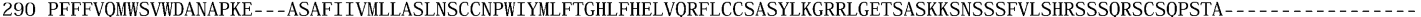
306 PFFIIOMWSVWDPMSVWTESENPTITITALLGSLNSCCNPWIYMFFSGHLLQDCVQSFPCCONMKEKFNKEDTDSMSRROTFYSNNRSPTNSTGMWKDSPKSSKSIKFIPVST - - - - . 296 PFFSVQMWSVWDKNAPDEDSTNVAFTISMLLGNLNSCCNPWIYMGFNSHLLPRPLRHLACCGGPQPRMRRRLSDGSLSSRHTTLLTRSSCPATLSLSLSLTLSGRPRPEESPRDLELADC

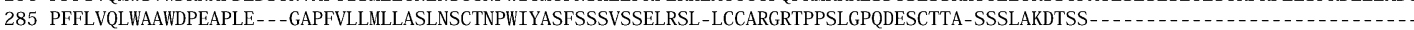

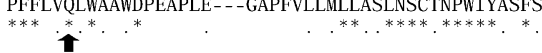

CTR

LSCPR1

LSCPR2

0T-human

V1a-human

V1b-human

V2-human

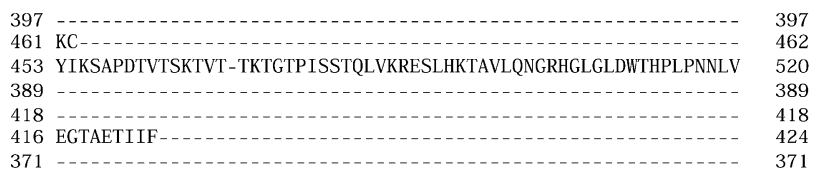

Figure 2 Sequence alignment of the orphan receptor (CTR) and receptors of the OT/VP superfamily. The amino acid sequence of the orphan receptor is aligned with those of Lymnaea conopressin receptors (LSCPR) 1 and 2 (van Kesteren et al. 1995, 1996), the human OT receptor (Kimura et al. 1992), the human V1a receptor (Thibonnier et al. 1994), the human V1b receptor (Sugimoto et al. 1994) and the human V2 receptor (Lolait et al. 1992). Amino acid residues that are identical in all receptors are indicated by an asterisk. Amino acid residues in boxes are highly conserved in the vertebrate receptors of the OT/VP superfamily, but not in other GPCRs, and have been suggested to be important in receptor-ligand interactions (Sharif \& Hanley 1992). Residues in the agonist-binding pocket described in the text are shown by arrows. Bars indicate the seven putative transmembrane domains.

(Fig. 3D). Thus the cloned receptor seems to be specific to $\mathrm{CT}$. The $\mathrm{EC}_{50}$ for CT was estimated from the doseresponse curve to be $14 \cdot 0 \pm 1 \cdot 7 \mathrm{nM}$ (Fig. 3C). This value is comparable to those for OT at the human OT receptor and Lys-conopressin at the LSCPR1, which are also expressed in Xenopus oocytes (Kimura et al. 1992, van Kesteren et al. 1995, 1996).

\section{Isolation of an endogenous ligand from Octopus brain}

To search for a genuine endogenous ligand for the cloned receptor, we assayed HPLC fractions of the Octopus subesophageal brain extract in oocytes expressing the cloned receptor. Three steps of HPLC yielded a single material that showed potent activity in the oocyte assay (Fig. 4). Apart from this material, no fractions exhibited active signals in the oocyte assay. The amino acid sequence of the purified material was X-Try-Phe-Arg-Asn-XPro-Ile-Gly ( $\mathrm{X}$ is an unidentified residue). Sequencing profiles at the first and the sixth cycles in a protein sequencer were similar to those of CT: the first halfcysteine at position 1 did not appear on the chromatogram, whereas the second half-cysteine at position 6 was detected as two specific peaks: the dithiothreitol adduct of PTH-dehydroalanine and PTH-Cys (Nokihara et al. 1990, Takuwa-Kuroda et al. 2003). The observed mass number, $535 \cdot 22[\mathrm{M}+2 \mathrm{H}]^{2+}$ in the nano ESI-TOF-MS analysis was very close to the mass number $(535.25$ $[\mathrm{M}+2 \mathrm{H}]^{2+}$ ) calculated for CT. Moreover, the fragmentation pattern of the isolated peptide in the TOF-MS/MS analysis was superimposable on that of CT. Taking these results together, we conclude that the cloned Octopus homologue of receptors of the OT/VP superfamily is the CTR. 
(A)

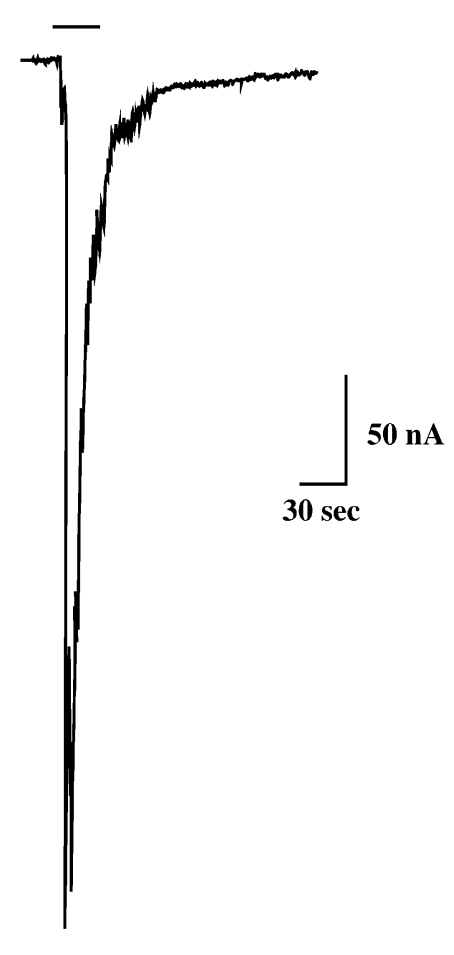

(C)

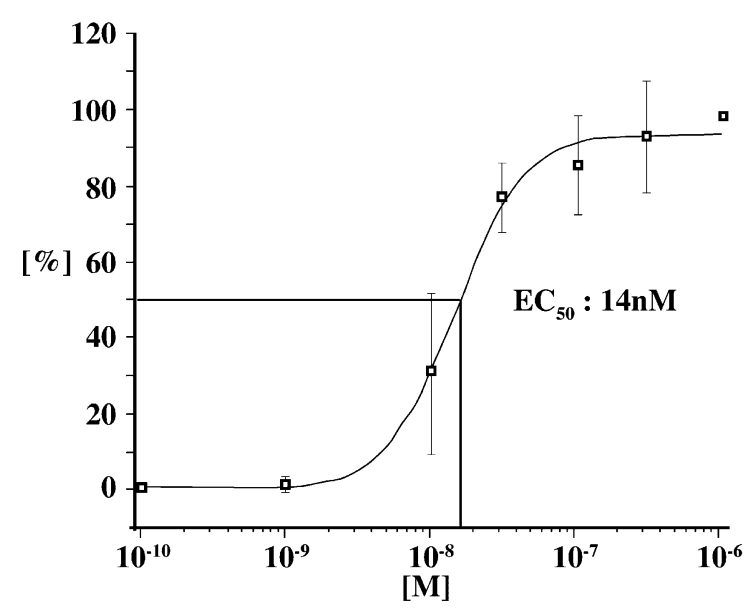

(B)

(D)

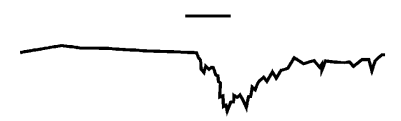

Figure 3 Functional expression of the cloned orphan receptor in Xenopus oocytes. (A) Membrane current induced by $\mathrm{CT}^{\mathrm{T}}$ at $10^{-7} \mathrm{M}$ in an oocyte expressing the receptor. CT was applied during the period indicated by the black bar. (B) No current was triggered by application of $10^{-6} \mathrm{M} \mathrm{OP}$, also indicated by a black bar. (C) Dose-response curve from the concentration range of $10^{-10} \mathrm{M}^{\text {to }} 10^{-6} \mathrm{M} \mathrm{CT}$. Maximum membrane currents elicited by CT are plotted. The current caused at $10^{-6}$ M CT was taken as $100 \%$. The mean of four independent experiments at each dose is shown with S.E.M. (error bars). (D) Membrane current elicited by $10^{-6} \mathrm{M}$ OT.

\section{Localization of CTR $m R N A$}

As CTR mRNA was not detected by northern blot analysis (data not shown), RT-PCR Southern blot analysis was performed to determine possible expression of the CTR genes in the central and peripheral nervous systems and in several peripheral tissues of Octopus. Figure 5 shows that CTR transcripts are present in the brain, the buccal ganglion, the gastric ganglion, the olfactory lobe and the peduncle lobe, the optic lobe, the pancreas, the oviduct and the ovary.

\section{Antagonists}

Many subtype-specific peptide or non-peptide antagonists of VP and OT have been developed to meet clinical demand. In this study, four peptide antagonists were tested to determine whether the activity of CT at the CTR expressed in oocytes was inhibited or not. An OT antag- onist $\left[\mathrm{d}\left(\mathrm{CH}_{2}\right)_{5}{ }^{1}, \operatorname{Tyr}(\mathrm{Me})^{2}, \mathrm{Orn}^{8}\right]-\mathrm{OT}$ at $10^{-5} \mathrm{M}$ showed no effects on the response to $10^{-7} \mathrm{M} \mathrm{CT}$ (Fig. 6A). The following antagonists, tested at $10^{-5} \mathrm{M}$, completely inhibited the response to $10^{-7} \mathrm{M} \mathrm{CT}$ (Fig. 6B, C, D): an OT antagonist $\left[\mathrm{d}\left(\mathrm{CH}_{2}\right)_{5}{ }^{1}, \operatorname{Tyr}(\mathrm{Me})^{2}, \mathrm{Thr}^{4}, \mathrm{Orn}^{8}\right.$, Tyr- $\left.\mathrm{NH}_{2}{ }^{9}\right]$-vasotocin; a V1 antagonist $\left[\mathrm{d}\left(\mathrm{CH}_{2}\right)_{5}{ }^{1}\right.$, $\left.\operatorname{Tyr}(\mathrm{Me})^{2}, \mathrm{Arg}^{8}\right]-\mathrm{VP} ;$ a V2 antagonist $\left[\mathrm{d}\left(\mathrm{CH}_{2}\right)_{5}, \mathrm{D}^{1} \mathrm{Ile}^{2}\right.$, $\left.\mathrm{Ile}^{4}, \mathrm{Arg}^{8}\right]-\mathrm{VP}$.

\section{Discussion}

We have previously shown that, in common with vertebrates, the common octopus, Octopus vulgaris, possesses two members of the OT/VP superfamily, OP and $\mathrm{CT}$ - the first time this was observed in invertebrates (Takuwa-Kuroda et al. 2003). As OP and CT have different biological activities, the presence of specific receptors has been proposed. We have cloned receptors of 

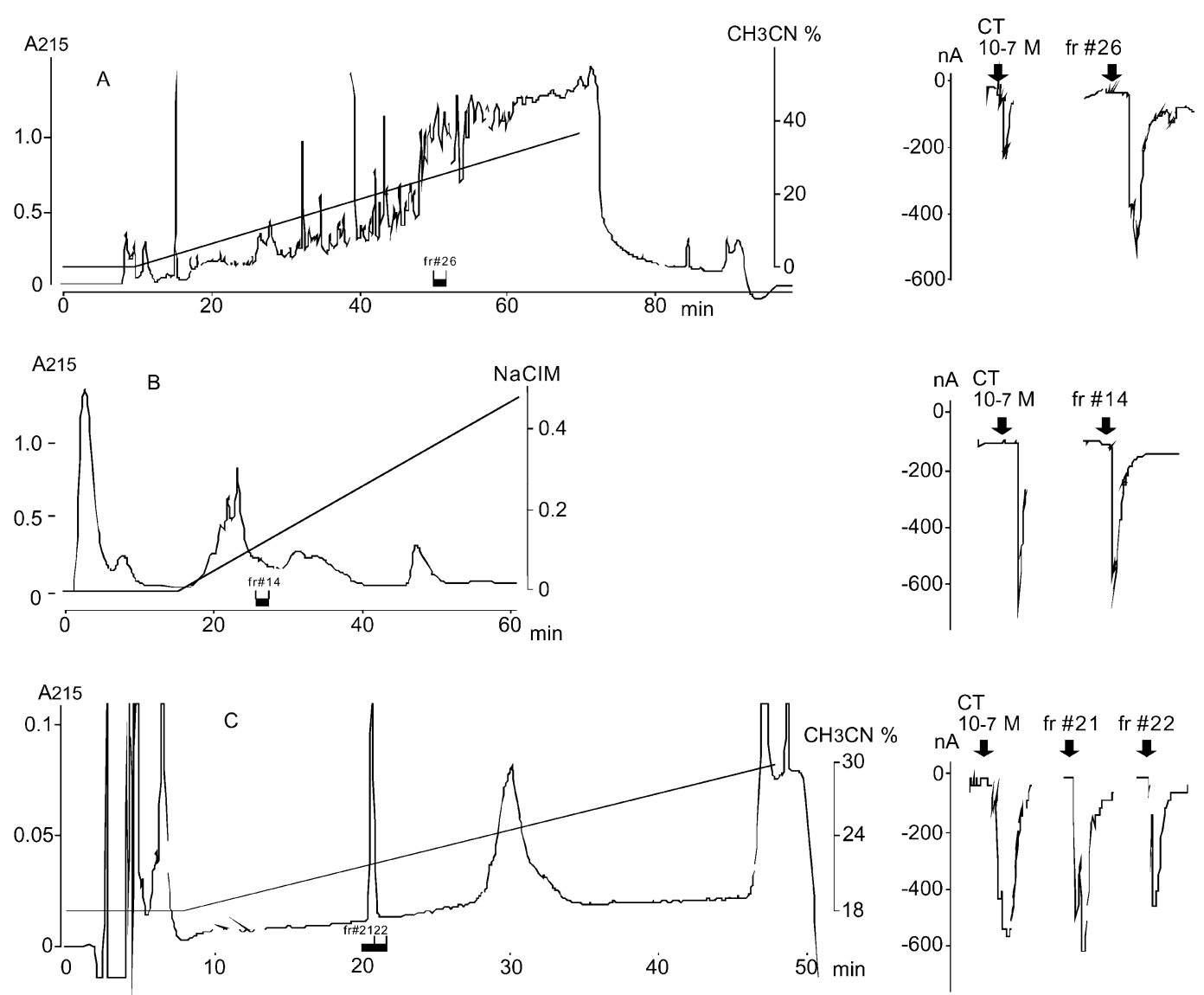

Figure 4 Purification of the endogenous ligand of the CTR from Octopus suboesophageal brain. (A) HPLC fractionation on a Capcell Pak UG80 column. Fraction 26 showed a $\mathrm{Cl}^{-}$current in the oocyte assay. (B) Fraction 26 in (A) was condensed in vacuo, dissolved in $20 \mathrm{mM}$ phosphate buffer, and injected into a cation-exchange HPLC with TSKgel SP-5PW column. Fraction 14 was active in the oocyte assay. (C) Fraction 14 in (B) was separated by a reversed-phase HPLC with a Capcall Pak C18 MG80 column. Fractions 21 and 22 both exhibited $\mathrm{Cl}^{-} \mathrm{Currents}$. The peak was outside the range of detection in the chromatogram and collected in two fractions, but a single material was eluted at the peak.

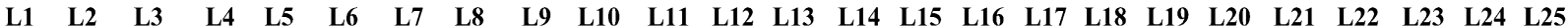

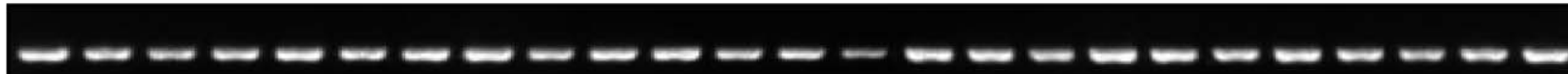

Figure 5 Southern blot analysis of RT-PCR products for CTR (upper panel) and actin (lower panel) transcripts isolated from the Octopus tissues. To exclude the possibility that a signal was caused by contamination with genomic DNA during RNA preparation, the PCR-Southern experiment was also performed without preincubation with reverse transcriptase (middle panel). L1: brain; L2: buccal ganglion; L3: gastric ganglion; L4: oesophagus; L5: crop; L6: stomach; L7: rectum; L8: aorta; L9: systemic heart; L10: salivary gland; L11: vas deferens; L12: testis; L13: optic gland; L14: olfactory lobe and peduncle lobe; L15: optic lobe; L16: kidney; L17: branchia; L18: liver; L19: pancreas; L20: white body; L21: egg; L22: branchial vessel; L23: oviductal ball; L24: oviduct; L25: ovary. 


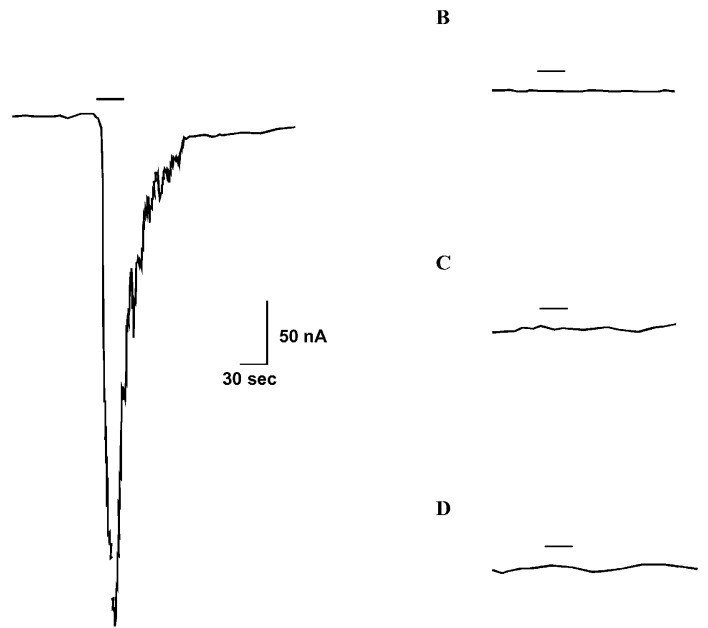

Figure 6 Effects of OT and VP antagonists on the response of oocyte-expressed CTR to CT. A mixture of CT $\left(10^{-7} \mathrm{M}\right)$ and an antagonist $\left(10^{-5} \mathrm{M}\right)$ was applied during the period indicated by the black bar. (A) OT antagonist $\left[\mathrm{d}\left(\mathrm{CH}_{2}\right)_{5}{ }^{1}, \mathrm{Tyr}(\mathrm{Me})^{2}, \mathrm{Orn}^{8}\right]$-OT. (B) OT antagonist $\left[\mathrm{d}\left(\mathrm{CH}_{2}\right)_{5}{ }^{1}, \operatorname{Tyr}(\mathrm{Me})^{2}, \mathrm{Thr}^{4}, \mathrm{Orn}^{8}, \mathrm{Tyr}^{\mathrm{N}} \mathrm{NH}_{2}{ }^{9}\right]-$ vasotocin. (C) $\mathrm{V} 1$ antagonist $\left[\mathrm{d}\left(\mathrm{CH}_{2}\right)_{5}{ }^{1}, \mathrm{Tyr}(\mathrm{Me})^{2}, \operatorname{Arg}^{8}\right]$-VP. (D) V2 antagonist $\left[\mathrm{d}\left(\mathrm{CH}_{2}\right)_{5}{ }^{1}, \mathrm{D}-\| l^{2}, \mathrm{Ile}^{4}, \mathrm{Arg}^{8}\right]-\mathrm{VP}$.

OP and CT from the Octopus brain by PCR amplification, using degenerate primers based on the amino acid sequences in the conserved transmembrane regions of the mammalian OT and VP receptors and Lys-conopressin receptors. The cloned orphan receptor is characteristic of a GPCR. Moreover, on the basis of amino acid sequence alignment and homologies in the transmembrane domains, the cloned receptor is suggested to be a homologue of receptors of the OT/VP superfamily.

The agonist-binding site for the OT and VP receptors has been suggested to be located in a narrow cleft delimited by the ringlike arrangement of the transmembrane domains (Mouillac et al. 1995). Five Gln residues in the transmembrane II, III, IV and VI and a Lys residue localized in transmembrane III are well conserved in all the OT and VP receptors (Mouillac et al. 1995) and are important for the interaction of OT and VP with their receptors (see Fig. 2). Four of them are also conserved in the cloned receptor $\left(\mathrm{Gln}^{102,125,179,315}\right)$. The remaining one, the $\mathrm{Gln}^{104}$ residue in the V1a receptor, is substituted by the analogous Asn ${ }^{98}$ residue. The Lys ${ }^{128}$ residue in the V1a receptor, which is proposed to interact with the Gln residue at position 4 in $\mathrm{VP}$, is substituted by a $\mathrm{Thr}^{122}$ residue. The residue at position 4 in $\mathrm{CT}$ is a basic one, Arg. It may be unfavourable for interaction if a basic side chain is present at position 122. However, the ligand of the cloned receptor was not clarified at this stage. The residues at position 8 in OT and VP are known to be necessary for their high-affinity and selective binding to their receptors. Molecular modelling of VP interaction with the V1a receptor supported the view that the side chain of $\mathrm{Arg}^{8}$ in VP projects outside the transmembrane core of the receptor and could interact with $\mathrm{Tyr}^{115}$ in the first extracellular loop (Chini et al. 1995). When the $\mathrm{Tyr}^{115}$ residue in the V1a receptor is replaced by Asp or Phe, the residue naturally occurring in the human V2 and OT receptors (see Fig. 2), a potent increase in V2 or OT agonist-binding affinities is induced (Chini et al. 1995). The Phe ${ }^{109}$ residue homologous to $\mathrm{Phe}^{103}$ in the human OT receptor is found in the cloned receptor. The residue at position 8 in $\mathrm{CT}$ and $\mathrm{OP}$ is Ile. Thus the cloned receptor seems to conserve the agonist-binding pocket common to OT and VP receptors.

Two adjacent Cys residues, which are found 15 residues downstream of transmembrane domain VII in the vertebrate OT/VP superfamily of receptors and LSCPR2 (van Kesteren et al. 1996), may be responsible for anchoring the C-terminus to the plasma membrane through palmitoylation (see Fig. 2). These Cys residues have also been observed for the $\beta$-adrenergic receptor (O'Dowd et al. 1989). However, palmitoylation does not seem to be important for receptor binding and signalling at the human V2 receptor (Sadeghi et al. 1995, 1997). That may also be the case in the cloned receptor, as only a Cys residue is present at the corresponding position in transmembrane domain VII.

Xenopus oocytes that express the orphan receptor responded to the application of CT by an induction of membrane $\mathrm{Cl}^{-}$currents coupled to the inositol phosphate $/ \mathrm{Ca}^{2+}$ pathway. OP and the other members of the OT/VP superfamily did not activate the expressed receptor. Only OT at $10^{-6} \mathrm{M}$ had any effect, and it was a weak one (see Fig. 3), which might be attributable to the conserved Phe ${ }^{109}$ in the receptor. HPLC fractionation of the Octopus brain extract, combined with the oocyte assay, yielded a single substance identical to CT (see Fig. 4). Thus it was revealed that the cloned receptor is the CTR.

\section{Expression of CTR $m R N A$}

Expression of CTR mRNA was detected in Octopus in the central and peripheral nervous systems, the pancreas, the oviduct and the ovary (see Fig.5).

In rats, OT receptors are abundantly present in several brain regions, namely some cortical areas, the olfactory system, the basal ganglia, the limbic system, the thalamus, the hypothalamus, the brain stem and the spinal code. OT and VP are considered to have pivotal roles in various aspects of sexual, social, feeding and learned behaviour (reviewed by Gimpl \& Fahrenholz 2001). The expression of the CTR gene in the brain may suggest the involvement of CT in neurotransmission, neuromodulation, or both, in the Octopus central nervous system. The expression of CTR in the optic lobe, the olfactory lobe and the peduncle lobe may suggest the role of CT in sensory systems such as vision and olfaction, and its expression in the 
buccal ganglion and the gastric ganglion may suggest a contribution of CT to feeding behaviour.

In the pancreas of mouse and rat, OT and VP increased the release of somatostatin, glucagon and insulin. OT and VP amplified glucose-induced release of insulin, probably via stimulation of phosphoinositide metabolism (Gao et al. 1991, Yibchok-Anun et al. 1999). In Lymnaea, insulinrelated peptides are released from neuroendocrine cells, light-green cells, which are located in the cerebral ganglion, and control carbohydrate metabolism. Lysconopressin induced a depolarizing response in the lightgreen cells, which express LSCPR1 (van Kesteren et al. 1995). Although insulin-related peptides have not been identified, and the presence of endocrine cells like the islets of Langerhans has not been investigated, in the Octopus pancreas, the expression of the CTR gene may be interesting from a comparative endocrinological point of view.

The ovary has been shown to contain OT, and may be a site of local production of OT in mammals (Ivell \& Richter 1984). Functional OT receptors have been detected in bovine granulosa cells, suggesting that OT may be an autocrine factor during follicular growth (Okuda et al. 1997). OT also increased the rate of mouse blastocyst development and might therefore play some part in the early stage of development of fertilized oocytes (Furuya et al. 1995). Although the levels of expression in the ovary are very low, CTR may mediate some of the processes in fertilization and early embryonic development in Octopus. The oviduct expressed the CTR gene, but CT had no contractile effects on the oviduct (Takuwa-Kuroda et al. 2003). The Octopus ovary sac contains various stages of oocytes. The mature eggs travel down the proximal oviduct into the oviductal gland, where they become encapsulated (Villanueva 1992). It is not unlikely that one of the activities in which CT may be involved in the oviduct might be maturation and encapsulation of eggs.

$\mathrm{CT}$ was also expressed in neurons in the ventral median vasomotor lobe. Some of these send out axons and form an extensive neuropile inside the vena cava in direct contact with the circulating blood, making a neurosecretory system (Takuwa-Kuroda et al. 2003). It is suggested that CT may be carried to peripheral tissues that express the CTR gene, not only by nerve fibres, but also by the bloodstream after being secreted into the vena cava.

\section{Response of the CTR to CT}

The response of the CTR to CT was inhibited by both OT and VP antagonists (see Fig. 6). V1 and V2 receptors are coupled to different signalling transduction systems and V1 and V2 antagonists used in this experiments show good selectivity for each of receptors. However, both antagonists completely inhibited the response to CT. This result means that the CTR does not conserve properties of V1 and V2 selectivity. Nevertheless, the CTR may not belong to any of the known subtypes of OT and VP receptors. The differences in amino acid residues, in the aromaticity at position 3 , and in the polarity at position 8 are believed to enable peptides of the OT and VP families to discriminate and interact with their respective receptors in vertebrates (Barberis et al. 1998). Such discrimination based on the residue at position 8 does not make sense in invertebrates (Satake et al. 1999, Takuwa-Kuroda et al. 2003). Both Lys-conopressin and its Ile-analog at position 8 could activate LSCPR 2 (van Kesteren et al. 1996). Both annetocin (Thr at position 8) and Lys-conopressin induced egg-laying-like behaviour in the leech (Fujino et al. 1999). Our findings in the present study suggest that peptides and receptors of the OT/VP superfamily in invertebrates do not follow the rule for vertebrates, but have their own alternative one.

In conclusion, we have cloned a novel receptor of the OT/VP superfamily that may mediate physiological functions such as neurotransmission, reproduction and metabolism in Octopus. Functional experiments show that the endogenous ligand for the cloned receptor is CT, and that the receptor can be slightly activated by OT, but not by other members of the OT/VP superfamily, including OP. As Octopus enjoys a highly developed brain and endocrine system, somewhat like vertebrates, it may have gained two OT/VP superfamily genes and specific receptors during the evolution of the molluscs.

\section{Acknowledgements}

The authors gratefully acknowledge Dr Terumi Nakajima (Professor emeritus, The University of Tokyo) for his encouragement of this work.

\section{Funding}

A part of this work was funded by Grants-in-Aid for Scientific Research from the Japan Society for the Promotion of Science to H M $(12640669,13024274)$.

\section{References}

Barberis C, Mouillac B \& Durroux T 1998 Structural bases of vasopressin/oxytocin receptor function. Journal of Endocrinology 156 223-229.

Bockaert J \& Pin JP 1999 Molecular tinkering of G protein-coupled receptors: an evolutionary success. EMBO Journal 18 1723-1729.

Chini B, Mouillac B, Ala Y, Balestre MN, Trumpp-Kallmeyer S, Hoflack J, Elands J, Hibert M, Manning M, Jard S et al. 1995 Tyr115 is the key residue for determining agonist selectivity in the V1a vasopressin receptor. EMBO Journal 14 2176-2182.

Fujino Y, Nagahama T, Oumi T, Ukena K, Morishita F, Furukawa Y, Matsushima O, Ando M, Takahama H, Satake H et al. 1999 Possible functions of oxytocin/vasopressin-superfamily peptides in annelids with special reference to reproduction and osmoregulation. Journal of Experimental Zoology 284 401-406. 
Furuya K, Mizumoto Y, Makimura N, Mitsui C, Murakami M, Tokuoka S, Ishikawa N, Nagata I, Kimura T \& Ivell R 1995 A novel biological aspect of ovarian oxytocin: gene expression of oxytocin and oxytocin receptor in cumulus/luteal cells and the effect of oxytocin on embryogenesis in fertilized oocytes. Advances in Experimental Medicine and Biology 395 523-528.

Gao ZY, Drews G \& Henquin JC 1991 Mechanisms of the stimulation of insulin release by oxytocin in normal mouse islets. Biochemical Journal 276 169-174.

Gimpl G \& Fahrenholz F 2001 The oxytocin receptor system: structure, function, and regulation. Physiological Review 81 629-683.

Gorbulev V, Buchner H, Akhundova A \& Fahrenholz F 1993 Molecular cloning and functional characterization of V2 [8-lysine] vasopressin and oxytocin receptors from a pig kidney cell line. European Journal of Biochemistry 215 1-7.

Hoyle CH 1998 Neuropeptide families: evolutionary perspectives. Regulatory Peptides 73 1-33.

Ivell R \& Richter D 1984 The gene for the hypothalamic peptide hormone oxytocin is highly expressed in the bovine corpus luteum: biosynthesis, structure and sequence analysis. EMBO Journal 3 $2351-2354$

Iwakoshi E, Hisada M \& Minakata H 2000 Cardioactive peptides isolated from the brain of a Japanese octopus, Octopus minor. Peptides 21 623-630.

van Kesteren RE, Tensen CP, Smit AB, van Minnen J, van Soest PF, Kits KS, Meyerhof W, Richter D, van Heerikhuizen H, Vreugdenhil E et al. 1995 A novel G protein-coupled receptor mediating both vasopressin- and oxytocin-like functions of Lys-conopressin in Lymnaea stagnalis. Neuron 4 897-908.

van Kesteren RE, Tensen CP, Smit AB, van Minnen J, Kolakowski LF, Meyerhof W, Richter D, van Heerikhuizen H, Vreugdenhil E \& Geraerts WP. 1996 Co-evolution of ligand-receptor pairs in the vasopressin/oxytocin superfamily of bioactive peptides. Journal of Biological Chemistry 271 3619-3626.

Kimura T, Tanizawa O, Mori K, Brownstein MJ \& Okayama H 1992 Structure and expression of a human oxytocin receptor. Nature 356 $526-529$.

Kyte J \& Doolittle RF 1982 A simple method for displaying the hydropathic character of a protein. Journal of Molecular Biology 157 105-132.

Lolait SJ, O'Carroll AM, McBride OW, Konig M, Morel A \& Brownstein MJ 1992 Cloning and characterization of a vasopressin V2 receptor and possible link to nephrogenic diabetes insipidus. Nature 357 336-339.

Mouillac B, Chini B, Balestre MN, Elands J, Trumpp-Kallmeyer S, Hoflack J, Hibert M, Jard S \& Barberis C 1995 The binding site of neuropeptide vasopressin V1a receptor. Evidence for a major localization within transmembrane regions. Journal of Biological Chemistry 270 25771-25777.

Nokihara K, Morita N, Yamaguchi M \& Watanabe T 1990 Routine determination of cystine containing peptides and proteins using protein sequencer, Shimadzu PSQ-1, with isocratic separation of PTH-amino acids. Proceedings of the 28th Symposium on Peptide Chemistry, Osaka, Japan. 159-164.
O’Dowd BF, Hnatowich M, Caron MG, Lefkowitz RJ \& Bouvier M 1989 Palmitoylation of the human beta 2 -adrenergic receptor. Mutation of Cys341 in the carboxyl tail leads to an uncoupled nonpalmitoylated form of the receptor. Journal of Biological Chemistry $2647564-7569$.

Okuda K, Uenoyama Y, Fujita Y, Iga K, Sakamoto K \& Kimura T 1997 Functional oxytocin receptors in bovine granulosa cells. Biology of Reproduction 56 625-631.

Probst WC, Snyder LA, Schuster DI, Brosius J \& Sealfon SC 1992 Sequence alignment of the G-protein coupled receptor superfamily. DNA and Cell Biology 11 1-20.

Reich G 1992 A new peptide of the oxytocin/vasopressin family isolated from nerves of the cephalopod Octopus vulgaris. Neuroscience Letters 134 191-194.

Sadeghi HM, Innamorati G \& Birnbaumer M 1995 Functional properties of mutant V2 receptors. In Neurohypophysis: Recent Progress of Vasopressin and Oxytocin Research, pp 445-451. Eds T Saito, K Kurokawa \& S Yoshida. Amsterdam: Elsevier.

Sadeghi HM, Innamorati G, Dagarag M \& Birnbaumer M 1997 Palmitoylation of the V2 vasopressin receptor. Molecular Pharmacology 52 21-29.

Satake H, Takuwa K, Minakata H \& Matsushima O 1991 Evidence for conservation of the vasopressin/oxytocin superfamily in Annelida. Journal of Biological Chemistry 274 5605-5611.

Sharif M \& Hanley MR 1992 Peptide receptors. Stepping up the pressure. Nature 357 279-280.

Sugimoto T, Saito M, Mochizuki S, Watanabe Y, Hashimoto S \& Kawashima H 1994 Molecular cloning and functional expression of a cDNA encoding the human V1b vasopressin receptor. Journal of Biological Chemistry $26927088-27092$.

Takuwa-Kuroda K, Iwakoshi-Ukena E, Kanda A \& Minakata H 2003 Octopus, which owns the most advanced brain in invertebrates, has two members of vasopressin/oxytocin superfamily as in vertebrates. Regulatory Peptides 115 139-149.

Thibonnier M, Auzan C, Madhun Z, Wilkins P, Berti-Mattera L \& Clauser E 1994 Molecular cloning, sequencing, and functional expression of a cDNA encoding the human V1a vasopressin receptor. Journal of Biological Chemistry 269 3304-3310.

Villanueva R 1992 Continuous spawning in the cirrate octopods Opisthoteuthis agassizi and O. vossi: features of sexual maturation defining a reproductive strategy in cephalopods. Marine Biology 114 $265-275$.

Yibchok-Anun S, Cheng H, Heine PA \& Hsu WH 1999 Characterization of receptors mediating AVP- and OT-induced glucagon release from the rat pancreas. American Journal of Physiology 277 E56-E62.

Received 3 July 2003

Accepted 1 August 2003

Made available online as an

Accepted Preprint 8 August 2003 